\title{
Development of Air Conduction Audiometer for Basic Hearing Screening
}

\author{
Kang-Ho Lee', Dongkyu Lee', Ohwon Kwon', Chul-Hee Choi ${ }^{2,3,4}$ \\ 'Daegu Research Center for Medical Devices, Korea Institute of Machinery and Materials, Daegu, Korea \\ ${ }^{2}$ Department of Audiology and Speech-Language Pathology, ${ }^{3}$ Research Institute of Biomimetic Sensory Control, \\ ${ }^{4}$ Catholic Hearing Voice Speech Center, Catholic University of Daegu, Gyeongsan, Korea
}

청력선별형 순음 청력검사기의 개발

이강호 ${ }^{1} \cdot$ 이동규 ${ }^{1} \cdot$ 권오원 $^{1} \cdot$ 최철희 ${ }^{2,3,4}$

한국기계연구원 대구융합기술연구센터 ${ }^{1}$, 대구가톨릭대학교 언어청각치료학과 ${ }^{2}$, 생체모방감각제어연구소 ${ }^{3}$, 가톨릭청각음성언어센터 $^{4}$

\begin{abstract}
Purpose: An air conduction audiometer was developed for basic hearing screening. This study introduces the hardware platform and development technologies. Methods: The developed platform includes a pure tone generator and tone switching method, which is capable of customizing the test frequencies and adjusting pure tone output level. Results: The developed audiometer was evaluated its performance according to the international standards. The pure tone output level was compared with conventional products. The attenuator shows good linearity with a deviation of $\pm 0.2 \mathrm{~dB}$. The output tone has a frequency error under $\pm 1 \%$ and total harmonic distortion of $0.44 \%$. Additionally, the audiometer was evaluated in terms of on/off ratio, crosstalk and rise/fall time during tone switching. Conclusion: Through audiometer development, we expect to increase the understanding of pure tone audiometric device and calibration knowledge.
\end{abstract}

Key Words: Pure tone, Air conduction, Audiometer, Frequency, Output level.

Received: June 7, 2016 / Revised: June 28, 2016 / Accepted: June 29, 2016

Correspondence: Chul-Hee Choi, Department of Audiology and Speech-Language Pathology, Research Institute of Biomimetic Sensory Control, Catholic Hearing Voice Speech Center, Catholic University of Daegu, 13-13 Hayang-ro, Hayang-eup, Gyeongsan 38430, Korea Tel: +82-53-850-2541 / Fax: +82-53-359-0780 / E-mail: cchoi@cu.ac.kr

\section{INTRODUCTION}

최근 다양한 휴대형 개인 음향기기에 노출이 잦아지면서 10 대 청소년의 소음성 난청률이 급격히 증가하고 있으며 전체 소 음성 난청 환자 가운데서 30대 이하가 차지하는 비율이 38\%나 되는 것으로 파악되고 있다(National Health Insurance Service, 2014). 또한 노인성 난청 인구의 현황을 살펴보면, 65세 이 상의 노인 가운데 $1 / 3$ 이상이 난청을 겪고 있는 것으로 세계보 건기구(WHO)가 보고하고 있다. 난청은 의사소통의 어려움을 가져올 뿐만 아니라, 자신감이 결여되고 우울증이 발생하는 등 의 문제로 발전할 수 있다(Kim \& Yeo, 2015; Kim et al., 2012; Jeong, 2014). 대부분 한 번 나빠지면 회복시키기 어렵기 때문에 청력이 더 나빠지지 않도록 예방하는 것이 가장 중요하다. 이를 위해서는 먼저 정확한 청력검사를 통해 본인의 청력손실상태를
평소 충분히 숙지하고 전문가의 도움을 통하여 이후의 치료 및 재활을 고려하는 것이 필요하다.

청력검사는 청력손실의 유무를 판별하고 그 정도와 유형을 평가하여 청력상태에 대한 기본적인 자료를 제공하는 것을 목 적으로 한다(Gelfand, 2009; Martin \& Clark, 2014). 이러한 청 력검사를 수행하기 위한 장치인 청력검사기의 경우, 2012년 한 국무역협회가 발표한 무역통계에 의하면 경쟁력이 매우 낮은 품목으로 지정될 정도로 대부분 수입에 의존하고 있다. 또한 산업경쟁력 실태조사에 따르면 청력검사용 기구의 수입증가율 과 무역특화지수를 고려할 때, 수입으로 인해 국내 산업의 피해 가 우려됨을 보고하고 있다(KIET, 2012). 따라서 본 연구에서 는 난청예방과 관련한 의료혜택을 확대하여 의료사각지대를 해소하고 청각산업의 확대 육성에 기여하고자 국내기술력을 바 탕으로 한 청력검사기의 개발을 수행하고자 한다. 
아직 우리나라는 인적 또는 물적으로 의료 인프라가 부족하 고 대도시 대형병원으로의 지리적 접근성이 떨어지는 의료소 외지가 많은 실정이다(Oh, 2013). 본 연구에서는 의료소외계층 을 위한 난청예방활동에 초점을 맞추어 출장 보건진료에 적합 하고 이동이 가능한 청력 선별(hearing screening)의 기능을 가지는 기도전도형(air conduction) 순음청력검사기(pure tone audiometer) 개발을 목표로 한다.

기도 전도형 순음청력검사기는 크게 순음발생장치(pure tone generator)와 출력 변환기(transducer)로 구성된다. 순음발생장 치는 가청 주파수 $(125 \sim 8,000 \mathrm{~Hz})$ 대의 순음을 발생시켜 다양 한 강도(intensity)로 이어폰 또는 헤드셋의 변환기에 소리를 전 달하는 역할을 담당하며 신호음의 강도를 증감시키는 강도조절 기(attenuator)와 신호음의 길이를 조절하는 단속기(interrupter switch)를 포함한다(Kim et al., 2015).

본 논문에서는 기도전도형 순음청력검사기를 구성하는 하드 웨어 플랫폼과 필요기술들을 소개하고 국제표준규격에 근거 하여 검사기의 성능을 평가한다. 청력검사기에 관한 본 연구는 검사기 동작과 교정에 대한 이해에 많은 기여를 할 것으로 기 대한다.

\section{MATERIALS AND METHODS}

본 연구에서는 순음발생장치의 기본이 되는 두 가지 기술 1) 주 파수별 순음발생기술과 2) 음 스위칭(tone switching) 기술에 대해서 소개한다. 본 기술을 통하여 소정의 주파수에 해당하는 순음의 공급과 순음출력강도(pure tone output level)의 조절이 가능해진다.

\section{순음발생기술}

본 연구에서 순음은 Figure 1에서와 같이 마이크로컨트롤러 제어 기반의 오디오 플랫폼에서 발생된다. $16 \mathrm{MHz}$ 클럭 기반 의 마이크로컨트롤러(atmega2560; Atmel corporation, San Jose, CA, USA)를 장착한 메인 유닛은 기본 연산 및 제어, 알
고리즘 처리를 주관한다. 오디오코덱(VS1053; VLSI Solution, Tampere, Finland)이 앞서 컨트롤러와 시리얼(serial) 통신으로 연결되어 순음 발생을 위한 사인파(sine wave)를 재생하고 컨 트롤러의 명령을 받아 볼륨 및 주파수의 가변을 수행한다. 여 기서 발생된 사인파 신호음은 오디오증폭기(audio amplifier)를 통하여 그 크기(magnitude)가 증폭된 뒤 외부로 전달된다. 출 력장치로 전달되는 오디오 신호는 차동신호(differential output)로 출력되며 이는 단일신호 출력(single-ended output)과 비교할 때 외부잡음에 강인하고 안정한 특징을 가진다.

기본적으로 순음발생장치는 검사하고자 하는 주파수를 자 유자재로 선택할 수 있어야 하며 출력강도의 조절이 가능해야 한다. 발생음의 주파수 설정방법과 범위는 Figure 2 와 같다. 8 비 트의 설정 레지스터에서, 상위 $3 \mathrm{bits}(7: 5)$ 는 설정 인덱스(index) 용으로 사용하고 하위 $5 \mathrm{bits}(4: 0)$ 는 세부 주파수를 결정하는 정보로 사용한다. 이 결과 최소 $93.75 \mathrm{~Hz}$ 에서 최대 $10,680 \mathrm{~Hz}$ 까지의 검사 주파수 인가범위를 가지게 되며 총 248 개 $\left(2^{3} \times 31\right)$ 의 주파수 설정이 가능하다. 여기서 서로 다른 인덱스에 해당하 지만 동일 주파수가 일부 중복 발생할 수 있으며 인덱스의 기 본 주파수는 오디오코덱에서 이미 고정되므로 변경 가능하지 는 않다. 또한 $5 \mathrm{bits}$ 세부주파수 결정 정보 가운데서 31개의 모 드만 주파수 설정에 사용한다. 본 연구에서의 선별용 순음청력 검사장치는 일반적으로 사용하는 검사 주파수 대역 외에도 다 양한 주파수 설정이 가능하여 연구 및 특수 진단과 분석에 용 이하도록 확장성을 가지고 있다고 할 수 있다

본 연구에서 개발한 청력검사기는 순음 출력강도의 조절을 위해 $32 \mathrm{bits}$ 크기의 레지스터를 이용한다. 레지스터의 상위 byte(= 16 bits)는 왼쪽 출력채널의 강도조절을 담당하고 하위 byte는 오른쪽 출력채널의 강도조절을 담당한다. 최대 출력강 도의 레지스터 설정은 $0 \times 00$ 으로 이루어지며 $0.5 \mathrm{~dB}$ 단계로 최대레벨에서 감소된다. 즉, 최대 강도에서 왼쪽 $-2.0 \mathrm{~dB}$, 오른 쪽 $-3.5 \mathrm{~dB}$ 이 되기 위해서는 $(2.0) /(0.5)=4,(3.5 / 0.5)=7$ 이므로 레지스터를 $0 \times 0407$ 로 설정하면 된다. 본 연구에서의 청력검사 기는 순음 출력강도가 최대에서 $-127 \mathrm{~dB}$ 까지로 설정 가능하다.

Figure 1. Description of hardware platform for air conduction audiometer. MCU: microcontroller unit.

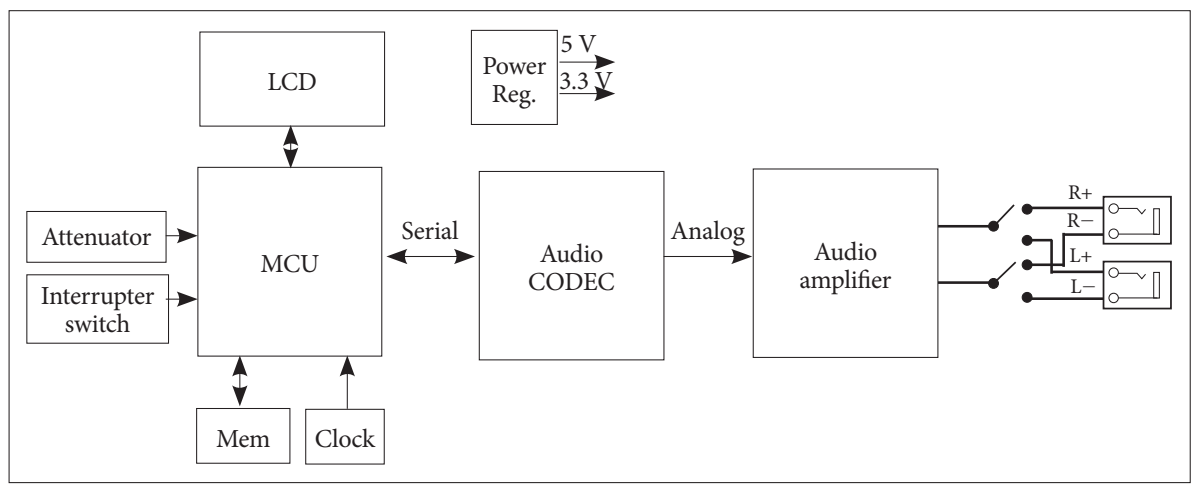




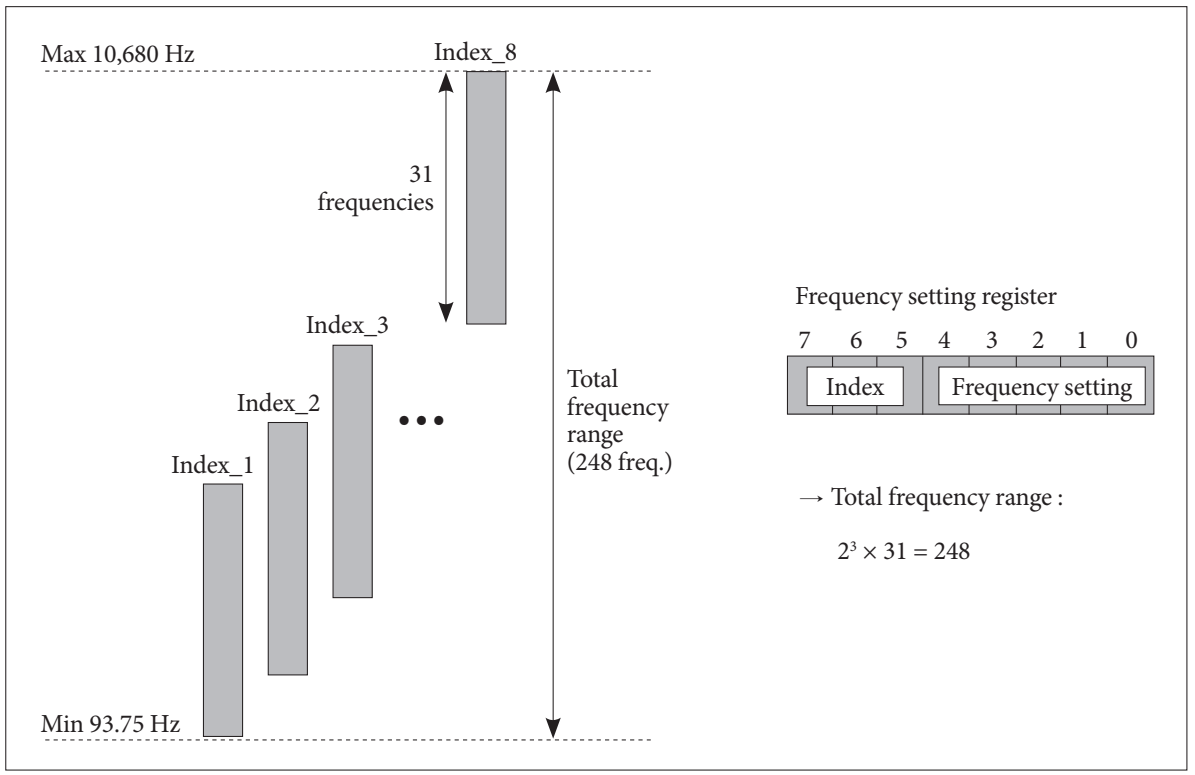

Figure 2. Setting register and allowable range for test frequencies in audiometer.
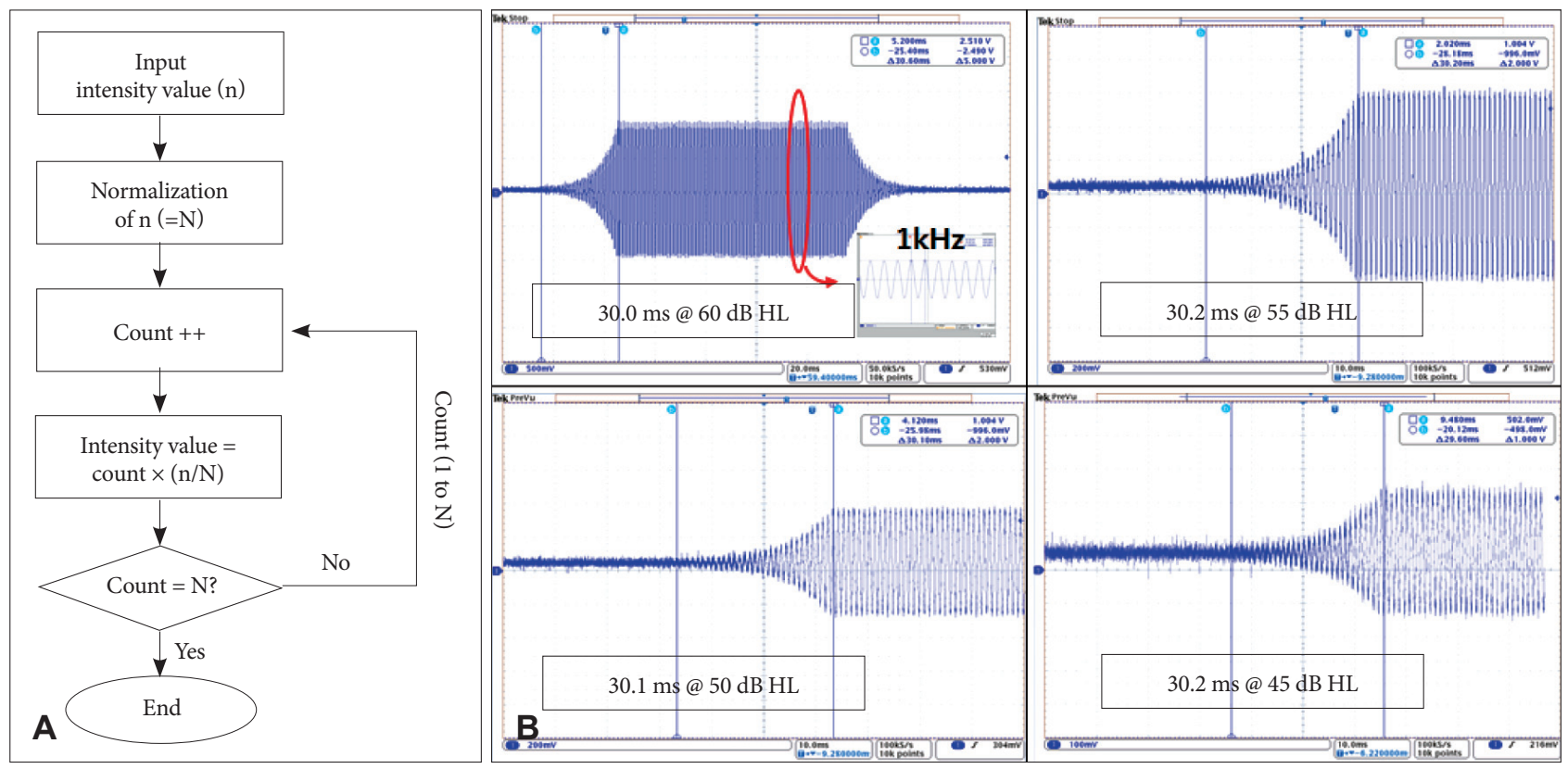

Figure 3. A: Proposed algorithm for a rise/fall time when pure tone generates. B: Measured waveforms as pure tone output levels change.

\section{음 스위칭 기술}

대부분의 청력검사기의 경우 음출력이 일반적으로 꺼져 있으 며 단속기(interrupter switch) 또는 음 스위치(tone switch)를 누르는 경우 순음이 출력장치를 통해 환자에게 전달된다. ANSI Standard(2010)에서는 환자가 다른 소리에 반응하지 않 고 발생한 순음에 대해서 선택성(selectivity)을 가지도록 점멸 비(on/off ratio), 혼선(crosstalk), 상승/하강시간(rise/fall time) 에 대한 성능 특성을 규정하고 있다. 본 연구에서는 순음출력 강도에 상관없이 발생음의 상승/하강시간을 유지할 수 있도록 하는 기술을 Figure 3A와 같이 제안한다(Lee et al., 2015). ANSI
Standard(2010)에 따르면, 청력검사기는 톤 발생 시 $20 \mathrm{msec}$ 이 상, $200 \mathrm{msec}$ 이하의 음의 상승 및 하강시간의 요구사항을 만 족하여야 한다. 먼저 순음출력강도에 영향을 받지 않으며 음의 상승/하강시간을 가지기 위해서는 입력된 강도의 셋팅 값을 정 규화(normalization)하는 작업이 필요하다. 이후 정규화한 최 대 강도가 될 때까지 일정시간 간격으로 계상(counting)하되, 각 카운트 시에는 가중치(= 강도세기 / 계상총량)를 곱한 세기의 강도를 출력한다. 뿐만 아니라, 제안한 방법에서 계상총량을 조 절하면 음의 상승 및 하강시간의 가변이 가능하다. Figure $3 \mathrm{~B}$ 는 순음 발생 시, 정상음 직전과 직후에 나타난 상승/하강시간 
을 오실로스코프(oscilloscope)를 통해 측정한 결과이다. 여기 서는 약 $30 \mathrm{msec}$ 의 시간으로 설정하여 $1 \mathrm{kHz}$ 신호음을 발생 시켰을 때 출력강도에 따른 음의 상승/하강시간 결과를 보여주 고 있다. 출력강도에 상관 없이 동일 시간을 유지하고 있으며 표 준규격 기준인 $20 \mathrm{msec}$ 이상 $200 \mathrm{msec}$ 이하를 충분히 만족하 고 있음을 확인할 수 있다.

\section{RESULTS}

\section{순음출력강도(pure tone output level)}

순음 청력검사기에서 출력강도를 의미하는 청력레벨(hearing level)은 사용된 출력장치와 커플러(coupler)에 따라 표준화된 기준역치강도(reference threshold level)로 교정되어야 한다 (Kim, 2016). 본 연구에서는 기도전도형 출력장치를 이용하므 로 음향 커플러(acoustic coupler)를 이용하여 기준등가역치음 압강도(reference equivalent threshold sound pressure levels, RETSPLs)를 기준으로 다음과 같이 교정되어야 한다(Kim \& Yeo, 2015). 먼저 이어폰 변환기(TDH-39, Telephonics Corporation, New York, USA)의 출력 음압(sound pressure level)을 소 음측정기(Type \#2250; B\&K, Nærum, Denmark)와 인공 귀 (Type \#4153, B \& K, Nærum, Denmark)를 사용하여 측정한 다. 청력검사기의 청력레벨은 앞서 측정한 음압에서 해당 출력 장치에 맞는 RETSPL 수치를 감하여 계산한 수치로 설정한다. Figure 4A는 제작한 청력검사기에서 발생되는 청력레벨과 IEC 60645-1(2012)에서 규정한 스크린용 청력검사기의 청력레벨, 상용 선별형 청력검사기 레벨을 서로 비교하고 있다(GSI 18, Grason-stadler, St. Paul, MN, USA; AS608, Interacoustics, Middelfart, Denmark). 제작한 청력검사에서 보여진 청력레벨은 표 준규격 기준(70 dB HL 이상)을 충분히 달성하며 기존 상용 검
사기와 비교할 때 유사한 성능수준에 해당한다.

\section{강도조절기 선형성(attenuator linearity)}

청력레벨을 조절하기 위해 강도조절기를 변화시킬 때 출력장 치의 순음출력강도도 동일한 크기로 변화해야 함을 보장하기 위하여 선형성에 대한 점검이 필요하다. 본 연구에서는 1,000 $\mathrm{Hz}$ 순음을 이용하여 순음출력강도를 최대로 설정하고 $5 \mathrm{~dB}$ 단 계로 감소시키면서 실제 출력되는 강도를 음향적으로 측정하였 다. ANSI Standard(2010)에 따르면, 감쇠기 간격 단계의 0.3 이 내 또는 $1 \mathrm{~dB}$ 중 더 작은 값으로 강도편차를 가지도록 규정하 고 있다. Figure $4 \mathrm{~B}$ 는 본 연구에서 개발한 청력검사기의 강도 조절기 조절에 대한 실제 출력되는 순음강도의 편차 $( \pm 0.2 \mathrm{~dB})$ 를 보여주고 있으며, 규격에 제시된 허용편차 $( \pm 2 \mathrm{~dB}$ 이내 $)$ 조 건을 만족함을 알 수 있다.

\section{주파수 정확도(frequency accuracy)}

순음청력검사기에서는 사용자의 검사주파수 입력에 대해 출 력된 주파수가 얼마나 정확하게 출력되고 있는지에 대한 점검 이 필요하다. IEC 60645-1(2012)에서는 정밀임상 또는 연구용 장비에 대해서 $\pm 1 \%$ 이내의 오차를 허용하고 있으며 스크린용 장비에 대해서는 $\pm 2 \%$ 이내 오차로 규정하고 있다. 본 연구에서 는 $70 \mathrm{~dB} \mathrm{HL}$ 을 기준강도로 하여 전체 주파수별 출력되는 음 향을 측정하여 정확도를 점검한 결과 최대 $0.92 \%$ 의 오차를 가 짐을 확인하였다.

\section{총 고조파 왜곡(total harmonic distortion)}

순음청력검사기에서 발생하고자 하는 검사 음의 주파수 이 외에 고조파 성분이 크게 존재하면 검사음의 충실도(fidelity) 가 낮아진다. 따라서 ANSI Standard(2010)에서는 총 고조파 왜
Figure 4. Measurement results. A: Pure tone output levels. B: Attenuator linearity.
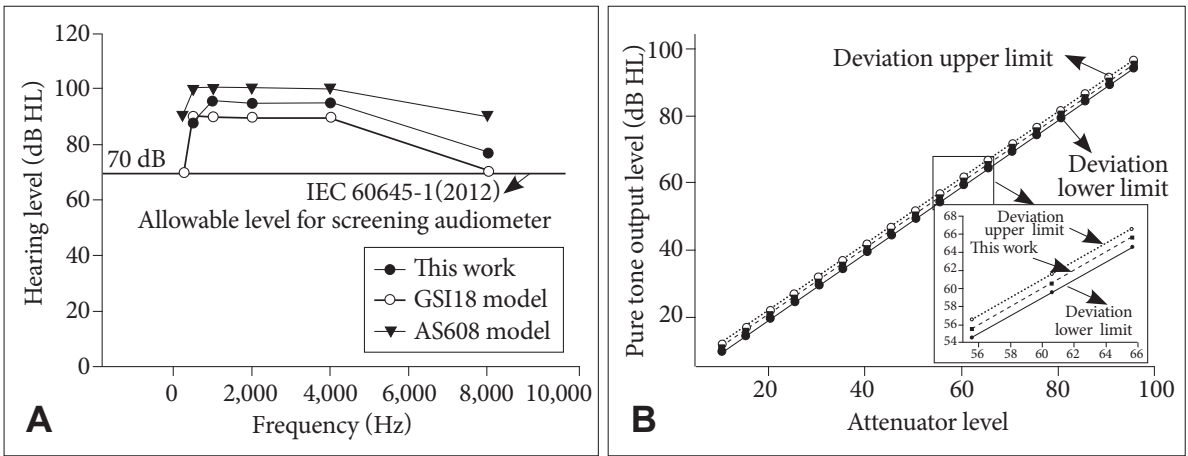

Table 1. Measured total harmonic distortion data

\begin{tabular}{lcccccc}
\hline \multicolumn{1}{c}{ Frequency $(\mathrm{Hz})$} & 250 & 500 & 1,000 & 2,000 & 4,000 & 8,000 \\
\hline Hearing level $(\mathrm{dB})$ & 90 & 95 & 95 & 90 & 90 & 90 \\
Total harmonic distortion $(\%)$ & 0.36 & 0.19 & 0.44 & 0.05 & 0.02 & 0.008 \\
\hline
\end{tabular}


곡의 규정을 두어 전 주파수 범위에서 최소 $2.5 \%$ 이하여야 함 을 제시하고 있다. 본 연구에서는 출력장치를 마이크로폰을 가 진 커플러와 연결한 후 음향신호를 오디오분석기(dScope Series III; PrismSound, Cambridgeshire, UK, England)로 입력함으 로써 총 고조파 왜곡을 측정하였다. 본 개발한 청력검사기는 최 대 $0.44 \%$ 의 왜곡을 가지는 우수한 특성을 보임을 확인하였다.

\section{음 스위칭}

순음청력검사기는 환자가 출력된 순음에 정확히 반응하도록 보장하기 위해 좌측 또는 우측 이어폰에 대해서 음을 생성시킬 때와 껐을 때의 출력강도의 차이를 점멸비 기준으로 판단하고 있으며, 양측 간 이어폰에서 혼선 잡음이 발생하는 지를 확인하 기 위해 혼선도에 대한 점검을 요구한다. 그리고 신호음을 발생 시, 정상음에 도달하는 데까지 걸리는 상승시간과 정상음으로 부터의 하강시간 조건을 규정화하고 있다. ANSI Standard (2010)에서는 점멸비 항목의 경우, $\leq 60 \mathrm{~dB} \mathrm{HL}$ 에서 음이 꺼져 있을 때 기준등가역치음압강도보다 $10 \mathrm{~dB}$ 더 낮게 출력되거나 또는 $60 \mathrm{~dB} \mathrm{HL}$ 을 초과하는 경우 $10 \mathrm{~dB}$ 을 증가시킬 때마다 10 $\mathrm{dB}$ 미만으로 증가해야 한다고 규정하고 있다. 일반적으로 점멸 비와 혼선에 대한 교정작업 시, 양측 이어폰으로 출력되는 신 호는 $70 \mathrm{~dB}$ 이상 차이를 보여야 한다. 본 연구에서는 순음출력 강도를 최대로 설정한 후 점멸비와 혼선을 점검한 결과, 100 $\mathrm{dB}$ (on/off ratio), $99 \mathrm{~dB}$ (crosstalk)의 수치를 각각 보였으며 이는 국외 상용장비 성능과도 비교할 만하다. 신호음 발생 시 상승/하강시간에 대한 측정결과는 앞서 Figure 3에서 보여주었 듯 출력강도에 무관하게 동일 시간을 유지함을 확인하였다.

\section{DISCUSSIONS}

본 연구에서는 청력선별검사를 위한 기도전도형 순음청력검 사기의 개발에 대해 소개하고 있다. 청력검사기의 경우 대부분 외산 장비가 수요를 독차지하고 있으며, 현재 국내 기술력으로 개발된 청력검사기는 없는 실정이다. 본 연구에서 제안한 선별 형 청력검사 플랫폼 기술을 바탕으로 하여 완성된 청력검사기 는 향후 국내 청각산업의 확대 육성과 건강검진 산업에서 새로 운 시장의 창출이 가능할 것으로 기대한다. 특히 본 연구에서 는 의료 혜택이 상대적으로 적은 지역에서 신속히 청력의 상태 를 측정할 수 있도록 출장보건을 위한 선별형의 청력검사기 개 발에 초점을 맞추고 있다. 의료소외지뿐만 아니라 작업장이나 학교, 의료 이동버스 내 비치하여 활용하는 것도 가능하리라 판단한다(Kim et al., 2004).

본 논문에서는 순음청력검사기를 구성하는 하드웨어 플랫 폼에 대해 소개하고 특히 가장 기본이 되는 두 가지 필요기술,
1) 주파수별 순음발생기술, 2) 음 스위칭 기술을 제안한다. 그리 고 개발된 청력검사기의 성능특성을 평가하기 위하여 표준에 근거하여 7개 항목으로 나누어 점검한다. 순음출력의 강도, 강 도조절기 선형성, 주파수 정확도, 총 고조파 왜곡, 음 스위칭 과 정에서 일어나는 점멸비, 혼선도, 생성음의 상승/하강시간 항목 으로 세분화하여 평가하였다. 본 연구에서 보여진 청력검사기 는 최대 $10,680 \mathrm{~Hz}$ 까지 총 248개의 주파수로 나누어 설정이 가능하고 $0.5 \mathrm{~dB}$ 간격으로 출력강도의 조절이 가능하다. 또한 음의 발생 시, 일정시간의 상승 및 하강을 확보하기 위해 새로 운 알고리즘을 제안하였다. 출력강도를 정규화한 후 가중치를 곱하는 방식으로 하여 출력강도에 무관한 음의 상승/하강시간 구현이 가능하였다. 청력검사기의 성능을 분석한 결과, ANSI Standard(2010)에 따르면 강도조절기에 대한 선형성을 판단할 때 $\pm 2 \mathrm{~dB}$ 이내의 편차가 허용되나, 본 청력검사기는 강도조절기 조절 간격에 대하여 실제 출력되는 순음강도의 편차가 $\pm 0.2 \mathrm{~dB}$ 이내인 우수한 선형성을 보였다. 출력되는 순음의 주파수와 입 력하는 주파수의 정확도를 살펴볼 때 최대 $0.92 \%$ 만의 오차 를 가지므로 허용기준 $\pm 1 \%$ 이내(스크린용 청력검사기의 경우 $\pm 2 \%$ 이내)임을 확인하였다. 발생음의 고조파 성분이 존재하여 기본음의 왜곡이 발생할 경우를 대비하여 총 고조파 왜곡을 조 사할 때 최대 $0.44 \%$ 로 표준규격에 제시한 $2.5 \%$ 의 허용기준을 만족하였다. 음이 스위칭하면서 일어나는 점멸비는 $100 \mathrm{~dB}$, 혼 선은 $99 \mathrm{~dB}$ 로 상용장비의 성능과도 비교할 만한 수준임을 확인 하였다.

본 연구에서 제시된 청력검사 하드웨어 플랫폼은 오픈소소 (Arduino, Italy) 기반으로 제작되어 가격이 낮고 누구나 쉽게 개발에 대한 접근이 용이한 장점을 가지고 있다. 따라서 본 청 력검사기를 관련 전문가 양성시간에 제작하여 볼 경우, 청력검 사기의 동작에 대한 이해를 더욱 높일 수 있을 것으로 기대한 다. 뿐만 아니라, 실제로 청력검사기의 교정은 정기적으로 실시 해야 하는 만큼 각 표준에 근거하여 제작한 검사기를 점검하여 봄으로써 보정(calibration)에 대한 경험을 쌓을 수 있을 것으 로 예상한다.

본 연구에서는 순음청력검사기를 구성하는 하드웨어 플랫폼 을 제안하였다. 앞으로 실제 검사프로토콜을 적용하여 환자와 의 상호 실험 후 결과가 반영될 때 최종 청력검사기가 완성되리 라 판단한다. 또한 검사자의 편의성을 고려한 제품 디자인의 설 계가 향후 필요할 것으로 보인다.

중심 단어 : 순음·기도전도·청력검사·주파수·출력강도.

\section{Acknowledgments}

본 연구는 대구가톨릭대학교의 연구비로 수행되었습니다. 


\section{REFERENCES}

ANSI Standard. (2010). ANSI/ASA S3.6-2010: Specification for audiometers. Washington, DC: American National Standards Institute.

Gelfand, S. A. (2009). Essentials of Audiology. (3rd ed.). New York, NY: Thieme.

IEC. (2012). IEC 60645-1:2012. Electroacoustics-Audiometric equipment Part 1: Equipment for pure-tone audiometry. Geneva: International Electronical Committee.

IEC. (2014). IEC 60318-3:2014. Electroacoustics-Simulators of human head and ear-Part 3: Acoustic coupler for the calibration of supra-aural earphones used in audiometry. Geneva: International Electronical Committee.

KIET. (2012). 2012 Industrial Competitiveness Survey. Sejong: Korea Institute for Industrial Economics \& Trade.

Jeong, S. W. (2014). The prospective effect of acceptance of disability on selfesteem of persons with hearing impairments. Disability and Employment, 24(1), 167-197.

Kim, J. D. (2016). Audiometric calibration of pure tone audiometers. Audiology and Speech Research, 12(1), 12-23.

Kim, K. S., Kim, J. H., \& Yoon, Y. H. (2012). The characterisitics of tinnitus and its relationship to depression from tinnitus acquired from military service. Korean Journal of Otorhinolaryngology Head and Neck Surgery, 55(12), 757-763.

Kim, K. S., Kim, H. R., \& Roh, J. H. (2004). Ambient noise levels in industrial audiometric testing areas: compliance with industry standards. Korean Industrial Hygiene Association Journal, 14(3), 311-318.

Kim, K. S., Kim, J. S., Kim, H. J., Bahng, J. H., Lee, K. W., Lee, J. H., et al. (2014). Introduction to audiology. Seoul: Hakjisa.

Kim, S. H. \& Yeo, S. G. (2015). Presbycusis. Hanyang Medical Reviews, 35, 78-83. http://www.arduino.cc.

Lee, K. H., Lee, S. A., Choi, K. S., \& Choi, C. H. (2015). Development of air conduction audiometer with screening. Korean Academy of Audiology, 2015, 164-167.

Martin, F. N. \& Clark, J. G. (2014). Introduction to Audiology. (12th ed.). New Jersey: Pearson.

National Health Insurance Service. (2014). 2008-2012_Noise-induced Hearing Loss (H83.3).

Oh, Y. H. (2013). Problem with and policy agenda for public health services in Korea. Seoul: Korea Institute for Health and Social Affairs. 